\title{
No more "Us" Versus "Others": Critique of Cultural Trauma in the Movie Partition by Vic Sarin
}

\author{
--Yog Raj Lamichhane \\ Assistant Professor of English, \\ Pokhara University, Nepal.
}

https://doi.org/10.3126/litstud.v34i01.39541

\begin{abstract}
On 15 August 1947, the glory of Indian Independence has introduced with a political hubris, dividing British India into two separate independent nations: secular India and Islamic Pakistan. The partition brings trauma in the life of millions; nevertheless, this trauma itself becomes the victim of nationhood and community both in official history and literary writing. In this background, the study examines how a Hollywood movie Partition directed by Vic Sarin in 2007, exceptionally surpasses that tendency of dividing the community into "as" and "others" imparting Indian partition trauma politically. While analyzing the behavior and action of major characters along with the overall imparted theme of the movie, it rethinks the customary archives of community and nationhood depicting partition memory objectively. The protagonist never pronounces a single word of communal intolerance even when he has been mocked and tortured in the name of religion. Conversely, some characters in the movie always attempt to massacre the truth of trauma spreading communal bile; however, the overall essence and message of the movie keep that alive. Rethinking cultural trauma and using the approach of memory, the study concludes that this in-between movie appears as "West Running Brook" that exceeds the common communalization and perpetual politicization in the history of depicting Indian partition. Eventually, the study establishes that sharing pain seems to work as a healer among victims to overcome their trauma on one side and uniquely it adjoins the British as a party in Indian partition trauma in the next, which has been blurred considering insignificant in the one-to-one conflict between two giants.
\end{abstract}

Keywords: Partition, Trauma, Cultural Trauma, Memory, Us and Others The Partition, Partition, and Trauma

The wonder of Indian autonomy becomes incomplete because of political hubris since British India falls apart into two separate sovereign nations: Pakistan and India. Capturing this issue in 2007, Vic Sarin directs a movie entitled Partition, which exceptionally surpasses the general tendency of dividing the community into "us", and "others" while recording Indian partition trauma.

The recollection of trauma in movies does not only project the individual pain of the victims but it attempts to situate "personal experiences in the historical context in which they take place (Sharma 499). Driving the audience to a particular time and space, a movie enters an individual trauma that may lead to collective experiences as well. However, even in imparting such personal experiences, politics has been already injected. Largely, the movies related to the Indian partition "invest heavily in the private sphere of emotions and familial relations. Nonetheless, far from depoliticizing history, it demonstrates that the private domain is already political. More often than not, the private sphere is a stand-in for the larger public categories of nation and state" (Viswanath and Malik 69). While doing so in a movie, they present the private sphere as a microcosm of a larger community or nation. 
The bloody riots of the division offer diverse topics for official history and trauma literature regarding the pain given by the watershed resulting in massive migration and mass slaughtering. Such themes of displacement and massacre are portrayed in cinematic form recollecting the memory and imagination. In such reminiscence, rather than approaching the truth, the Indian partition literature and movie from both Indian and Pakistan equally have the mastery to blame others as the cause of violence. Ausima S. Malik and Raja N. Akhtar situate that Indian and Pakistani literary text and movie related to partition associate each other as the cause of violence, "suppressing much of what transpired, evading any clear position, while promoting triumphant discourses of nation, sacrifice, and socio-economic insinuations" (521). No party emboldens to review oneself with a certain degree of realization. A study to ascertain the pedagogy of Indian partition literature by Beerendra Pandey in the light of trauma theory concludes that " the literature of trauma does not necessarily offer a means of overcoming instability, contaminated as it is with the ideological contours of the dominant culture to which the trauma belongs" (136-137). Rather than dealing with the traumatized subject individually and objectively, the literature gives the impression of politics dealing with the subjects collectively as official history in quantity.

Different from the psychological trauma, cultural trauma snowballs the wound and pain of an individual to an extended community and gets the shape of politics. In cultural trauma, "a tear in the social fabric, writes Ron Eyerman, affecting a group of people that have achieved some degree of cohesion". In the case, people identify themselves to the victim and encourage them to identify themselves to particular culture sobbing together to communalize the subject. Sometime it may work for sympathy and empathy but in most cases, it downsizes the traumatized subject and fulfills the political motive someone else.

Gyanendra Pandey, an Indian revisionist, disregards the general tendency of recording partition trauma politicizing "violence in their past by the relatively simple stratagem of drawing a neat boundary around themselves, distinguishing sharply between 'us' and 'them', and pronouncing the act of violence an act of the other or an act necessitated by a threat to the self" (177). In this way, most of the texts skew to the authors' culture involving in other psychological partition. They erect the wall of "us" and "others" and the public space subjugates the private space in partition movie as well to sensitize individual audience through reel serving communal subject, sanitizing the real trauma.

Keeping all these in the background, the study inspects the anti-current depiction of partition trauma in the movie Partition that does not dissect the community to "as" and "others" surpassing the general trend. Essentially the ideas of Jeffery Alexander on cultural trauma, the concept of Cathy Caruth on psychological trauma, and revisionist notions of Gyanendra Pandey on [against] nationalist myth-making regarding Indian trauma are synthesized with the evidence from the movie using the script managed by www.scripts.com to strengthen the argument made earlier. History might be exclusive, but it becomes the duty to literature, especially oral archive, to rescue the subject from the exclusion. Overcoming the limitations of the official archive as a quantitative recorder of partition violence, (Chakravarty 100), the movie as an alternative archive alongside the official historiography discourages cultural trauma and depicts the objective memories of the partition trauma, embedded in the scars of the sufferers' mind and body. The Invisible Scars of Partition Violence 
Declaring partition of India along with her independence has brought massive migration of Muslims in Islamic Pakistan and Hindu plus Sikh in secular India. The hatred against each other has been breaking in form of violence and riots in different parts of Pakistan and India. However, these are unheard that the "trauma of partition has been eclipsed by the celebration of independence" (Nigam 2013). The official histories from both sides are reluctant to enter into such an area. Nevertheless, startlingly transcending the indulgence to partition riot, some memories are indifferent to the violence and genocide advocating cooperation, peace, and reconciliation as portrayed by the Hollywood movie Partition directed by Vic Sarin. The movie does not teach politics and conspiracies regarding the partition, rather it replicates the trauma of partition through beholders and endures. The expression turns into a "black box", a basis of ultimate voice for understanding (Berger 571) the effectively liable and the utmost reliable party to reveal memory that is communicated with no more "us" versus "others" in the movie.

The history of partition resembles the history of trauma. Gian Singh, the protagonist of the movie, resigns the job in British Army and returns to his village Sirsa in Punjab when he has already been traumatized by the death of a friend in the Second World War. While working in the field, there he observes a massacre fueled by Sikh as a larger mass of Muslims fleeing to Pakistan. Avatar, probably the planner of that cruel attack, a close friend of Gian even in the Army, from his same locality hints him "I watched you yesterday. You have been busy working on the farm while others have done your parts" (Sarin 00:16:31-00:16:35) . The update of Avtar to Gian about the portion of his actions regarding violence has been done by other friends explains that, in Gyanendra Pandey's understanding, some specific memories of cruelty go on forming 'community'(4) to politicize it. Avtar does so. However, Gian inquires with confusion and digression, "My part? What? Killing innocent people? They got what they deserve. For me, there is no compromise" (Sarin 00:16:35-00:16:42). He belongs to the Sikh community but loves, respects every people as human, and opposes the idea of killing innocent people in the name of religions. Conversely, Avtar again motivates Gian to stand against Muslims, telling him that he has not done his job as Sikh from his side. Gian never compromises with his belief in violence and lives as a black ship in society. He stands neither to Sikh nor to Muslims but with humanity apolitically.

The enmity among different communities in partition time bears truth but there consists love and respect to the people from other communities as well. Gian meets a teen Muslim girl Naseem Khan in the bush close to his field where the riot has happened. She has been hiding there to save herself from abdication and potential rape in that massacre. The presence of Gian scares her as she has been separated from her family. Gian convinces, "I will not hurt you. You cannot stay here" (Sarin 00:18:5500:19:22). Being a Sikh, he provides shelter to a Muslim girl in such political turmoil and a terrifying situation. He takes risks for humanity and tolerance. Avatar who is watchful and disappointed with these approaches him again saying, "Come on. You have to see the train, which had arrived from Pakistan to see what has happened on the train from Pakistan. We need more people. People who were soldiers, Gian. Join us" (Sarin 00:22:32- 00:23:45). The train has been carrying the dead bodies of brutally killed Hindu and Sikhs from Pakistan. Avatar takes Gian there to arouse the hatred against Muslims and insists on him to participate in communal violence. In such a terrifying circumstance, the people from Gian's community try to handle the situation using "relatively simple stratagem of drawing a neat boundary around themselves, 
distinguishing sharply between 'us' and 'them', and pronouncing the act of violence an act of the other or an act necessitated by a threat to the self (Pandey 177). However, they fail to do so in the case of Gian. When Gian returns to his home, his mother feels overwhelmed by the murder of her friend Rani's family on that train. At the same time, she expresses satisfaction, "I'm so glad you're not involved, my son". She condemns the violence ruthlessly but she neither participates nor encourages involvement in such brutality. Gian and her mother differentiate themselves from violence and religious tolerance guides as moral code for them.

Offering shelter to the people from different communities stands parallel to inviting risk in such turmoil situation. One day, a mob knocks the doors of Gian violently. No one answers the door. Avatar aggressively orders from the horse's back, "Destroy the door, where is Muslim?"(Sarin 00:31:06- 00:31:15). They have come there because of the presence of the Muslim girl in the house. Gian defends, "She is a Girl. She is not responsible for those deaths" (Sarin 00:31:15-00:31:24). Gian believes that people might be from any religion but innocent people should not be penalized because of the wrongdoing of other members from any religion. Rani, a victim of partition violence rebukes, "My son, his wife, his children, my grandchildren! They kill them damn Muslims! How dare you hide one of them among us? Do you know what they did to our children on the train? (Sarin 00:31:32 -00:31: 42). That is true; she has been bearing irreparable loss in her life. She wants to take revenge communalizing the violence involving in "a reworking of collective memory" (Eyerman 1). Her attempt to give collective identity to her trauma promotes communalization. When Avtar proactively attempts to enter into Gian's house, Gian threatens Avtar that if he goes into his house, one of them will be deceased (Sarin 00:31:51- 00:31:56). Avtar shows patience and the mob hesitates to enter inside. At last, they bargain some money; Gian gives whatever he has. Their tolerance saves them from a potential crash. Hence, Gian could resist forcefully as he has been strengthened by moral soundness and his nonaligned standpoint to ongoing violence.

The partition of the nation has affected the forbearance and this division appears into the level of drinking water too. Once, Naseem goes to a well to fetch water. Rani shouts, "How dare you come to our well. For you, there is no water. Go fetch it from Pakistan" (Sarin 00:43:09 00:43:14). Her "our" is so congested that Naseem could not be incorporated there. The communal politics come up to drinking water, a public resource. Gian's mother appears there to cool down Rani, telling that she might be anyone but she is going to fetch water for her son. At the same time, a girl argues, "Water belongs to everyone" (Sarin 00:43:17- 00:43:19) supporting Naseem and the mother of Gian. After some days, there comes Holy. All look busy in enjoying. Exploiting the opportunity, a young Sikh, who has active participation in the previous riot, follows and attempts to abuse Naseem. For the second time, Gian saves her to be listed in 75,000 sexually exploited women at the time of partition (Butalia 3). This night, her traumatic memory reappears as theorized by Cathy Caruth that the reminiscence of a shocking occurrence might be lost over time although it comes back when activated by a parallel occurrence (186- 187). After a couple of days, Gian receives a letter from Margaret to whom he has requested to find out the address of Naseem's family in Pakistan. There lies the reference of her brother Andrew at last. The flashback of his inefficiency to save Andrew as promised to Margaret triggers him into trauma as already observed in the case of Naseem. Tonight, both of them share their traumatic experience, to quote Beerendra Pandey's words, which "helps the victims and survivors comfort it 
and works through it" (128). The sharing works as a healer for them to overcome their trauma. In such chaotic social and political circumstances too, their love and respect for each other bring them closer and closer day by day.

The enduring efforts of some morally committed characters can change the community. This tolerant couple in the movie, Gian and Naseem marry being free from the religious taboo and have a son named Vijaya. Suddenly, Margaret appears in Gian's house with good news for Naseem: the address of her family close up to Lahore and the credentials for her travel (Sarin 1:06:04-01:06:15). Using the papers managed by her, she visits Pakistan to meet her alienated family for a month with a return ticket too. Gian has waited for her for three months. There in Lahore, her brothers have confined her to go back to India as Siobhan Lambert-Hurley indicates that the Muslim women's voice is more marginalized (119) and even the people of their religion (Butalia 3) sometimes victimize the women. When she intends to return, her brother Akbar blames Gian, "They kill our father" (Sarin 1:17:03-1:17:05). Saying so, he drags the total Sikh community as a murderer and adduces his community as a sufferer. Cultural trauma, to quote Jeffrey C. Alexander, "occurs when members of a collectivity feel they have been subjected to a horrendous event that leaves indelible to marks upon their group consciousness, marking their memories marks upon their group consciousness, forever and changing their future identity in fundamental and irrevocable ways" (6). Guided by such group consciousness, her brothers engage to communalize the murder of his father. Even so, Naseem stands against this observation and defends Gian as the savior of her life. She alleges, "My husband did not kill anyone! He saved my life" (Sarin 01:17:05- 01:17:10). She discourages to politicize the violence opposing cultural trauma.

Geographical and religious boundaries fail when love and respect drive someone to humanity. As generally understood that everything becomes fair in love, Gian enters Pakistan illegally crossing fences and converting as Muslim in search of Naseem. There he has to encounter her aggressive brothers first. Her brother Akbar violently beats and bitterly scolds:

My sister with a chic!

How dare you come into our home?

How dare you?

Murderers!

You killed my father!

You attacked and massacred us as we Belial. (Sarin 01:30:17$01: 30: 37)$

Akbar squeals Gian calling the murderer: not a Muslim but a Sikh, yet, he has named himself as Mohammed Hasan. He never listens to him. All the time, he tries to draw a line between communities relating to religion. About such politicization of the trauma, Alexander says, "societies expand the circle of the 'we'. For the same reason, social groups can, and often do, refuse to recognize the existence of others' trauma or place the responsibility for it on people other than themselves. Because of their failure, they cannot achieve a moral stance" (6). Such formation of "we' excludes many. Such politics comes into sight in form of aggressive assertion always downsizing and even denying others' trauma. In Gyanendra Pandey's view, mainstream history creates 'truth' of partition trauma and violence (45) rather than depicting as it is. The deconstruction of that inefficiency or disinterestedness of historians to show objective memories can be a better correction. The movie also strives to assess the history of pain and suffering 
reporting the marginal characters of the society rather than creating political and cultural truth.

The one who advocates reconciliation never forgets the lessons of tolerance even in any adverse situation. Only a few people understand such generosity whereas many others in the world of communalized 'we' interpret it as a weakness. Gian, who has been living with a broken heart, responds Akbar expressively:

If the crime was being born as a Sikh,

It is a crime to be born as a Muslim. I do not want to hear this.

Half my life I was a soldier.

I fought for India. For Sikh, Muslims,

Hindus, Christians, for all ...

Yes, I killed people. Lots of them.

I returned home to find peace and found the division.

Hatred everywhere. I did not want to be part of it.

The day I found my...

I could not leave there that someone else was found.

I had to save her. But Naseem is actually saved me. (Sarin

01:30:53- 01:31:58)

Nevertheless, Akabar has beaten Gian challenging his dignity and identity, Gian does not pronounce a single word of hatred. Neither, he fights with him. Moreover, he asks "questions about how the 'us' and 'them' are constituted" (Pandey 197). The pathetic expression of Gian in the light of Pandey's idea describes how the politics of separating society into "us" versus "them" hurls him not acknowledging trauma. Keeping the love and mutual respect at the center, he requests not to politicize religious identity. Dissecting the politics of cultural trauma which flows "a tear in the social fabric" (Everyman 2), Gian endures the pain but never allows or encourages others to establish any cohesion in his trauma. He appeals to rethink the culture of dividing people in the name of community and religion. Disregarding division and detestation, he promotes peace and reconciliation. He considers that the religious identity of an individual should not be the reason for hatred.

The third party of the partition, which has a legacy to England, supports Gian. Margaret and Walter as the representatives of this third pole prop Gian to release him from the custody of Lahore and they facilitate Naseem to escape from Pakistan. When Naseem and Gian coincidently behold each other from the distance in the train station, her brothers appear there chasing their sister. They do not allow them to enjoy the reunion for a longer time. Akabar throws Gian down from a height (Sarin 01:42:2001:42:25). Gian dies advocating eternal love, social integrity, and religious tolerance. The death of the husband takes her to trauma again. Naseem and her son catch a train with Margaret. Finally, all three come into sight in England.

Margaret, who has been living in India/Pakistan disregarding the last words of her caring brother to return to England before his death on the battlefield also leaves India/Pakistan. Trauma plays a major role in her decision making to return to England. Her trauma is uniquely different from commonly understood bipolar trauma that the movie allocates the space for the third party in trauma beyond the trauma of Indian and Pakistani or Hindu, Sikh, and Muslim. Regarding the marginalization of the pain and suffering of women, Anne Castaing argues that no history has read the stories, which are inscribed in their body and mind because of the physical, figurative, and psychological 
violence (164-165). The history of the nationhood and the communalized depiction of trauma undermine the physical and psychological stigma of women because of that, their stories remain unwritten. However, the movie shows the victimization of females in partition through Naseem and Margaret who have been living with stigma and full of untold stories of suffering.

Finally, Naseem reports the viewers that Avtar scatters the ash of Gian around the trees of the village. That indicates respect to the values of Gian and Avtar's active participation in scattering the ash around the local trees signals that he has just changed. In this regard, Naseem believes, "His roots are deep in the earth" (Sarin 01:45:47 01:45:49) at the end of the tragic story. In this context of remembering partition, Pierre Nora supposes that the shift "from memory to history" demands all societies reinterpret their subjectivity in the course of renewing past accounts (15). In processing doing so, her remembering becomes a form of historiography.

Emergence of Third Pole in Trauma The Hollywood movie Partition blurs the general trend of politicizing the partition trauma teaching peace and humanity. It develops empathy within the audience to the victims of partition as an archive of tolerance rather than communalizing. The protagonist, Gian Singh has already been traumatized as he fails to protect Andrew on the battlefield since he has promised Margaret to protect him. After the resignation from the military, he risks rescuing a lady from the Muslim community, Naseem from a field of a partition riot. They both traumatized subjects marry without enforcing each other for conversion and the marriage becomes a means of overcoming their trauma. However, more adverse days have left to come in their lives. Gian and Naseem receive torture just because of being from a particular community but extraordinarily they never pronounce a single word of hatred blaming any community. It indicates that the history of partition is not only full of abduction, killing, and disgust; rather there exists eternal love, social integrity, and religious tolerance. It is Remarkable when the trauma surpasses the politics of "us" and "others" in the movie, there appears a trauma of a third party as well. The silent trauma of a character named Margaret who has British root comes into the scene, as the movie come out of the bilateral lingering politics of trauma. Distinctively, sharing pain seems to work as a healer among victims to overcome their trauma in the case of Gian and Naseem at first and Margaret later. The study adjoins the British as a member of Indian partition trauma, which has been left away considering irrelevant in a straight clash between two giant communities. The presence of Hollywood might be the cause of such different depictions of partition trauma that should be confirmed through comparative study integrating more samples.

\section{Works Cited}

Alexander, Jeffrey C. Trauma: A Social Theory. John Wiley \& Sons, 2013.

Berger, James. "Trauma and Literary Theory." Contemporary Literature, vol. 38, no. 3, 1997, pp. 569-582. JSTOR, www.jstor.org/stable/1208980.

Butalia, Urvashi. The Other Side of Silence: Voices from the Partition of India. Penguin UK, 1998.

Caruth, Cathy. "Unclaimed Experience: Trauma and the Possibility of History." Yale French Studies, no.79, 1991, pp. 181-192. JSTOR, www.jstor.org/stable/2930251.

Castaing, A. "Poetics of Pain: Writing the Memory of Partition."Partition and the Practice of Memory, edited by Churnjeet Mahn and Anne Murphy, Palgrave Macmillan, 2018. pp.155-171. https://doi.org/10.1007/978-3-319-64516-2 
Chakravarty, Pallavi. "The Story of Partition from the Official and the Alternate Archives."Partition and the Practice of Memory, edited by Churnjeet Mahn and Anne Murphy, Palgrave Macmillan, 2018. pp. 91-113. https://doi.org/10.1007/978-3-319-64516-2_5.

Eyerman, Ron. Cultural Trauma: Slavery and the Formation of African American Identity, Cambridge University 2001. https://doi.org/10.1017/CBO9780511488788.001

Lambert-Hurley S. "Narrating Trauma, Constructing Binaries, Affirming Agency: Partition in Muslim Women's Autobiographical Writing."Partition and the Practice of Memory, edited by Churnjeet Mahn and Anne Murphy, Palgrave Macmillan, 2018, pp. 115-136. https://doi.org/10.1007/978-3-319-64516-2_6.

Malik, Ausima S., and Raja Nasim A. "Role of Cinema in Identity Construction in India and Pakistan after Partition 1947." Review of Economics and Development Studies, vol. 5, no. 3, 2019, pp. 521-530. https://doi.org/10.26710/reads.v5i3.660.

Nigam, Aditya. "Between Memory and History." Economic and Political Weekly, vol. 39, no. 20, 2004, pp. 2013-2014. JSTOR, www.jstor.org/stable/4415024.

Nora, Pierre. "Between Memory and History: Les Lieux De Mémoire." Representations, no. 26, 1989, pp. 7-24. JSTOR, www.jstor.org/stable/2928520.

Pandey, Beerendra. "Pedagogy of Indian Partition Literature in the Light of Trauma Theory." Southern Postcolonialisms: The Global South and the 'New' Literary Representations, edited by Sumanyu Satpathy, Routledge, 2009, 124-138.

Pandey, Gyanendra. Remembering Partition: Violence, Nationalism, and History in India. Vol. 7. Cambridge University Press, 2004. Sarin, Vic. "Partition" YouTube, uploaded by Tina Pehme and Kim Roberts, 14 Aug. 2019, https://www.youtube.com/ watch? $=$ sMJQ44ln3Qk.

Sharma, Manoj. "Cinematic Representations of Partition of India."People: International Journal of Social Sciences, vol. 3, no. 3, 2017, pp. 492-501. https://doi.org/ 10.20319/pijss.2017.33.492501

Viswanath, Gita, and Salma Malik. "Revisiting 1947 through Popular Cinema: A Comparative Study of India and Pakistan." Economic and Political Weekly, vol. 44, no. 36, 2009, pp. 61-69. JSTOR, www.jstor.org/stable/25663519. 